\title{
ФИПОСОФСКИЕ HАYKИ
}

\section{ОПРЕДЕЛЕНИЕ РЕЛИГИОЗНЫХ ЦЕННОСТЕЙ В КОНЦЕПЦИИ ИОАХИМА ВАХА}

\author{
Козлова Ирина Львовна \\ магистр религиоведения, старший преподаватель кафедры религиоведения, \\ Российский православный университет святого Иоанна Богослова \\ 2. Москва \\ DOI: 10.31618/ESU.2413-9335.2019.6.61.45
}

\section{DEFINITION OF RELIGIOUS VALUES IN THE CONCEPTION BY JOACHIM WACH}

\author{
Kozlova Irina Lvovna \\ Master of Religious Studies, Senior lector at Department of Religious Studies \\ St. John the Theologian's Russian Orthodox University
}

Moscow

\begin{abstract}
АННОТАЦИЯ.
В статье представлен фрагмент религиоведческой концепции Иоахима Ваха. Анализируются его понимание религиозного опыта и критерии для определения этого опыта. На основании определения И. Ваха автор статьи выводит критерии дефиниции религиозных ценностей, которые рассматриваются им как высшие или предельные ценности. Отмечается важность осознанности в процессе определения высших ценностей, а также понимания того, что стремление к предельности является антропологической универсалией, имеющей свое значение в межрелигиозных диалогах.
\end{abstract}

ABSTRACT.

The article presented the fragment of Joachim Wach's conception of the studies of religion. His understanding of religious experience and the criteria for definition this experience is analyzed. Based on the definition of $\mathbf{J}$. Wach, the author of the article deduces the criteria for the definition of religious values, which he regards as the supreme or ultimate values. The importance of awareness in the process of determining of the supreme values and understanding, that the intention to ultimacy is the anthropological universality, having the value in interreligious dialogues, is noted.

Ключевые слова: религиоведение; Иоахим Вах; высшие ценности; аксиология; религия; псевдорелигия; секуляризм; религиозный опыт; предельная реальность.

Keywords: religious studies; Joachim Wach; supreme values; axiology; religion; pseudo religion; secularism; religious experience; ultimate reality.

Статья написана по материалам доклада, представленного И. Л. Козловой в 2018 году на конференции «Истина как нравственная ценность», проводившейся в рамках XXVI Международных Рождественских образовательных чтений, основная тема которых звучала как: «Нравственные ценности и будущее человечества». На секции «Религиозные ценности и современная цивилизация» были рассмотрены современные исследовательские концепции, связанные с актуальными проблемами религиоведения, аксиологии, социологии, теологии, культурологии, в том числе концепция, представляемая в данной статье.

Иоахим Вах (1898-1955) - это германо-американский мыслитель, который считается классиком академического религиоведения, внесшим существенный вклад в создание этой науки и в формирование ее методологического аппарата. Его творчество хорошо освещено в современном зарубежном религиоведении, но недостаточно пока известно в российских научных кругах по причине почти полного отсутствия переводов его текстов.

Этот человек родился в Германии. Он происходит из рода еврейско-немецкого философа Моисея (Мозеса) Мендельсона (1729-1786), который за- нимался экзегетикой и переводом библейских текстов и оказал большое влияние на развитие идей просвещения и реформизма в иудейской среде. Отец Иоахима Ваха был внуком немецкого композитора Феликса Мендельсона (1809-1847), автора известного вальса Мендельсона. Семья Феликса Мендельсона приняла лютеранство вскоре после его рождения. Унаследовав традиции своей семьи, И. Вах с детства был христианином (в четвертом поколении). Однако это не спасло его от преследования нацистов, которому он подвергся из-за своих еврейских корней, и в 1935 году 37-летний ученый был вынужден эмигрировать в Америку, где вдали от оставшихся в Германии родных (матери, сестры и брата) провел вторую часть своей жизни.

Современный российский религиовед Андрей Павлович Забияко писал, что: «И. Вах был одним из пионеров осмысления новых вызовов христианству» [2, с. 131]. В его трудах был намечен контур религиоведческого изучения псевдорелигий и феномена секуляризма. Для различения религиозных и псевдорелигиозных явлений И. Вах ввел четыре формальных критерия, на которых базируется его понимание религиозного опыта и религии [см. 9, p. $27-58 ; 10$, p. 30-47]. В контексте взаимоотношений нравственных и религиозных ценностей, а также 
рассмотрения истины как нравственной ценности, эти критерии представляют, на наш взгляд, немалый интерес и для современных исследователей. В трудах самого И. Ваха нет прямых указаний для определения религиозных ценностей как таковых. Это определение мы выводим из предложенной И. Вахом дефиниции религиозного опыта. В статье мы рассмотрим, как И. Вах отличал религии от псевдорелигий, и как его понимание религиозного опыта может помочь нам в определении религиозных ценностей.

Религию И. Вах определял как опыт священного [8, p. 13]. Опыт священного, или религиозный опыт, в понимании И. Ваха, это такой опыт, в котором человек переживает встречу с некой высшей силой, независящей от человека и неизмеримо превосходящей все имеющиеся в нем силы, подконтрольные его уму и возможностям. Опыт такой встречи становится для человека источником и основанием всех его жизненных сил и ценностей, и человек ищет способы переживать подобный опыт снова и снова. Для обозначения этой высшей силы И. Вах использовал термин «ultimate reality». Переводить и трактовать его можно по-разному: высшая реальность, предельная реальность, последняя реальность, окончательная, максимальная, абсолютная, основная, безусловная, конечная, ультимативная. Мы остановимся на переводе «предельная реальность».

В терминологии И. Ваха религиозный опыт это опыт встречи с предельной реальностью. В его понимании этот опыт является первичной данностью, фундаментом-основой любой религии, ее имплицитной установкой. Генетически концепт «предельная реальность» восходит к «нуминозному» Рудольфа Отто. В целом подход И. Ваха можно охарактеризовать как теологический. Проводя различие между религиозным и псевдорелигиозным опытом, религиовед отмечает, что псевдорелигии могут проявлять черты подлинной религии. Единственное различие между ними наш автор видел в том, что псевдорелигиозный опыт имеет в своей основе не предельную, а какую-то иную реальность. В псевдорелигиях обычные человеческие реалии возводятся в ранг высших (предельных) ценностей и становятся смыслообразующим началом, т.е. обожествляются, становятся идеалами и идолами.

Среди реалий своего времени И. Вах выделял четыре типа псевдорелигиозности [см. 9, p. 37-38; 10, p. 33]. Первый - это марксизм с его хилиазмом и экономической теорией в основе. Второй - это биологизм, для которого высшей ценностью является культ жизни как таковой или культ полового влечения. Третий - это популизм или расизм, в которых божественный характер приписывается этнической, политической или культурной группе. Четвертый тип - это этатизм, в котором высшей ценностью является прославление государства. Все четыре типа И. Вах объединяет под общим термином «секуляризм», противопоставляя таким образом религиозное и секулярное.
Подобные работы по осмыслению и классификации псевдорелигиозных явлений велись впоследствии и другими авторами. Например, Пауль Тиллих, продолжая мысль И. Ваха, пишет: «все, что становится делом безусловного интереса, превращается в некоего бога» [4, с. 161]. И далее поясняет примерами: «Если нация является чьим-либо предельным интересом, то название нации становится священным именем, и сама нация наделяется божественными качествами, которые во многом превосходят реальное бытие и жизнедеятельность нации. Нация в этом случае подменяет и символизирует истинно предельное, но только идолопоклонническим образом. Успех, ставший предельным интересом, - это не то же самое, что естественное желание актуализировать свои потенции, это уже готовность принести в жертву все остальные жизненные ценности ради достижения власти и социального господства» [4, с. 161-162].

Итак, основное различие между религией и секуляризмом в концепции И. Ваха заключается в том, что именно является предельной ценностью, фундирующей чувства и действия человека или сообщества. Факт встречи с предельной реальностью в концепции И. Ваха выступает в качестве первого формального критерия для определения религиозного опыта. Этот критерий мы будем называть «предельным импульсом». Таким образом, религия и секуляризм различаются в том, какая реальность дает человеку предельный импульс. Чтобы понять, в чем эти явления схожи, посмотрим на остальные три критерия И. Ваха.

Второй критерий свидетельствует о том, что переживание встречи с предельной реальностью затрагивает не одну какую-либо сторону человеческого существа, например, интеллектуальную, эстетическую, моральную, волевую, этическую или социальную, а касается всех составляющих человеческой личности, захватывает все его бытие. Это состояние предельной захваченности и устремленности к тому, что воспринимается человеком как предельная реальность, мы будет называть «предельным интересом».

Третий критерий говорит о том, что все части человеческой личности, захваченные предельным интересом, приобретают состояние предельной активности и максимально мобилизируются. Встреча с предельной реальностью не только интегрирует человеческую личность, но и максимально стимулирует все ее составляющие. Этот критерий мы будем называть «предельным усилием».

Объединив объемы понятий, в которые мы заключили содержание второго и третьего ваховского критериев, то есть «предельный интерес» и «предельное усилие», мы получим содержание, которое зафиксируем под названием «предельная мотивация». Это понятие будет выражать субъективную сторону опыта, который определяется критериями И. Ваха как опыт религиозный.

Четвертый критерий, как и первый, характеризует объективную сторону религиозного опыта. Этот критерий свидетельствует о наличии какого- 
либо действия, акта, выражающего религиозное переживание. И. Вах был убежден, что встреча с предельной реальностью несет в себе побудительный императив. Поэтому истинное религиозное переживание непременно стремится излиться во вне, то есть объективировать себя, и потому неминуемо выражается в действии. Формулируя эту мысль И. Ваха другими словами, скажем, что, то, относительно чего человек не испытывает потребности к выражению, то есть к артикуляции в речевом или в деятельном акте, религиозным переживанием не является. Этот критерий мы будем называть «предельным актом».

Возвращаясь к вышесказанному, напомним, что религиозный и псевдорелигиозный опыт в концепции И. Ваха различаются первым критерием. Остальные три критерия делают практически тождественными религиозный опыт и некий другой опыт, который мы будем называть «предельным опытом». Основная характеристика предельного опыта - это наличие действия, совершенного под влиянием предельной мотивации, которая складывается из предельного интереса и предельного усилия. Нужно сказать еще несколько слов о том, какие действия можно отнести в категорию предельных. Представляется, что в первую очередь это акты, связанные со смертельным исходом, и потому представляющие угрозу безопасности отдельных людей и обществу в целом. Например, самоубийства, убийства, фанатизм, экстремизм, терроризм и др.

Критерии И. Ваха позволяют зафиксировать некоторое специфическое состояние, назовем его «состоянием предельности», которое одинаково свойственно религии и секуляризму. Объяснение этому можно найти в антропологической концепции И. Ваха, согласно которой стремление к предельности заложено в структуре человеческого естества, то есть является неотъемлемым признаком, свойством человеческой природы [10, p. 32]. В одной из своих работ И. Вах иносказательно пишет о «религиозном органе», помогающем человеку понимать и чувствовать содержащийся в религиях призыв, смысл и ценность [7, s. X-XI]. Это позволяет не только переживать религиозный опыт, но распознавать его в других, что особенно важно для религиоведа, а также для людей, встречающихся в своей деятельности с религиозным фактором.

Состояние предельности - это переживание, выраженное в предельном действии, или действие, совершенное под влиянием предельного переживания. Если человек совершает предельный акт, руководствуясь религиозными ценностями, его действие попадает в разряд религиозных. Если предельный акт совершен под воздействием мотивации, сформированной человеческими ценностями, то действие секулярное. Разница между ними - в первом критерии, то есть в источнике предельного импульса, выражаясь введенными нами терминами. Основной вопрос - что для человека является предельной реальностью, то есть источником предельных ценностей. Какие ценности являются для него высшими, то есть предельными, к чему он готов направить все силы своей жизни, ради чего он готов умереть или отдать все, что имеет, чему он готов посвятить и подчинить всю свою оставшуюся жизнь, что положит в основу своего бытия.

Критерии И. Ваха - это критерии по своей сути теологические, об этом пишет, например, Энн Тейв3 [3]. Они были сформированы в рамках конкретного религиозного дискурса. При таком подходе к определению религии и секуляризма И. Вах, безусловно, прав. С точки зрения христианина, все ценности, кроме христианских, будут недостаточными для того, чтобы занять место высшей ценности, а значит, в иерархии ценностей они будут ниже по рангу, то есть подчиненными. Подобное можно сказать и о других традиционных религиях. Например, для мусульманина высшие ценности имеют иную смысловую окраску, чем высшие ценности христианина, также и для иудея или представителя других верований. Понятия псевдо-, квази-, пара- и полурелигий рождаются в рамках теологических дискурсов, поэтому вопрос об истинности той или иной религии неразрешим во внеконфессиональном поле.

Опираясь на концептуальную схему И. Ваха можно сказать, что каждая религия уверена в том, что ее, именно еe, религиозный комплекс базируется на истинном опыте встречи с предельной реальностью. Что это может означать? Если принять за истину, что предельная реальность одна, то выражение опыта встречи с ней может иметь только одну конкретную форму, а все остальные, отличающиеся от этой, формы выражения, будут свидетельствовать об опыте встречи с реальностью, которую назовем «псевдопредельной». Если принять за истину, что предельных реальностей много, и каждой соответствует своя форма выражения, то мы получим релятивистическую модель, в которой исчезнет сущностный признак понятия «предельная реальность», а именно, ее абсолютность и уникальность.

Пытаясь разрешить данное противоречие, И. Вах говорил о том, что «культурные традиции следует понимать, как типологически разные способы упорядочения различных человеческих возможностей и различных реакций человека на предельную реальность» [9, p. xxv]. Эта мысль базируется на его убеждении в том, что предельная реальность одна, но ответ человека может быть разным. Это то, что И. Вах назвал «вечная человечность» [9, р. хxv; 6, s. 8-9]. Вечная человечность утверждает бесконечность потенциальных возможностей человеческой природы, которые могут быть по-разному актуализированы в различных исторических формах обществ и культур.

В завершении статьи представим некоторые соображения о том, чем в наше время могут быть полезными изложенные тезисы концепции И. Ваха. В современном мире активно трансформирующихся культур существует много различных ценностных систем. Конфигурация каждой из них различна, и у каждой на вершине разные ценности. Источник высшей ценности, становится для человека божеством, основой и смыслом жизни, его предельной реальностью. Ценности являются важнейшим системообразующим фактором, способствующим консолидации людей в группы. Они напрямую связаны с интересами, потребностями и идеалами. Но 
что делать, когда ценности разные, особенно высшие, предельные? В такой ситуации они не будут выполнять интегрирующую функцию, а станут причиной конфликтов. Примеров тому можно привести множество, от бытовых несогласий в семейном кругу до религиозных войн мирового масштаба.

Когда раб или слуга убивает человека чтобы подтвердить верность и преданность своему хозяину, это говорит о том, что в его ценностной системе жизнь одного человека и жизнь другого человека являются разными по значению. Когда подросток убивает себя из-за того, что его союз с избранником невозможен, как в классической истории с Ромео и Джульеттой, это может свидетельствовать о том, что источником предельной ценности является конкретный человек, а высшей ценностью отношения с ним. Когда слепая родительская любовь поддерживает инфантильность в ребенке в ущерб его самостоятельности, чтобы подольше с ним не расставаться, это тоже может быть примером того, как отношения с другим человеком предельно ценны, а ребенок в этих отношениях является источником предельной ценности, то есть своего рода божеством, ради которого родители готовы на все. Когда человек посвящает всю свою жизнь какому-то одному делу, потому что об этом его просил на смертном одре его умирающий отец (или мать), это тоже может быть свидетельством того, что предельная реальность открылась человеку в момент смерти его близкого. Когда в семье на протяжении нескольких десятков лет возникают конфликты из-за того, какой праздник считать самым главным, Пасху или Новый год, или как лучше проводить выходные, на даче или в храме, это не только говорит о том, что физически близкие люди живут в разных ценностных системах, но и о том, что конфигурации этих систем отличаются и предельные ценности тоже, то есть семейные традиции или религиозные.

Цепочку примеров можно продолжить, но на этом остановимся и приведем в качестве иллюстрации известное изречение человека, почитаемого как святого католической, православной и лютеранской конфессиями. «Мучеником делает не наказание, но причина: прежде он выбирает причину и затем претерпевает наказание» [1, с. 111], - пишет библейский комментатор, цитируя Августина Блаженного. Это высказывание Августина относится к библейскому сюжету о двух разбойниках, которые были распяты вместе с Иисусом Христом.

Это очень характерный, на наш взгляд, пример, который показывает, как одно и тоже действие (смертная казнь) может иметь разное значение в зависимости от того, кто совершает это действие (умирает) и почему. Выражаясь в терминологии, использованной нами при интерпретации критериев И. Ваха, предельный акт в вышеозначенной ситуации одинаков для всех трех участников, но предельные мотивации разные. Разбойник выбрал причину своего поступка, и его последствия стали для него наказанием. Христос был движим другим мотивом, и его акт стал мученическим. Пример покаявшегося разбойника показывает, как предельный акт может изменить свою смысловую окраску по причине изменившейся интенции совершившего его человека. Перед лицом предельной реальности он переосмыслил свои ценностные ориентации и получил прощение, осознанно поставив на вершину своей ценностной системы другую истину.

Очень важным здесь представляется осознанность. Она необходима человеку для формирования умения определять свои высшие ценности, а также принимать тот факт, что у другого они могут быть внешне иные, но по сути тоже предельные. Четкое понимание того, что стремление к предельности заложено в каждом человеке, но выражаться оно может по-разному, поможет находить точки соприкосновения при осуществлении межконфессиональных, межрелигиозных и межкультурных диалогов. Если принять утверждение И. Ваха, что предельная реальность одна, но ответы разные, то форма этих ответов будет зависеть от волевого выбора и индивидуальных особенностей человека или человеческой общности. В этом выборе важно подобрать разумную меру сочетания личной цели и социальных обязательств, так как и то и другое базируется на высших ценностях. А если понимать ценности как «отношение между представлением субъекта о том, каким должен быть оцениваемый объект, и самим объектом» [5], то кто из нас может уверенно утверждать, что именно он обладает самым адекватным представлением о той Предельной Реальности, которая является причиной, основой и смыслом всего человечества в целом?

\section{Список литературы:}

1. Библейские комментарии отцов Церкви и других авторов I-VIII веков. Новый Завет. Том Ia: Евангелие от Матфея 1-13. - Тверь: Герменевтика, 2007. - 432 c.

2. Забияко А.П. Теологические трактовки квазирелигий: Концепции И. Ваха и П.Тиллиха // Проблема демаркации науки и теологии: современный взгляд. - М.: ИФ РАН, РГГУ, 2008. - С. 126143.

3. Тейвз Э. Религиозный опыт [Электронный pecypc] / пер. с англ. и прим. Т.В. Малевич // Портал «Религиозная жизнь». - URL: http://religiouslife.ru/2012/11/religious-experience/ (дата обращения 17.04.2019)

4. Тиллих П. Избранное: Теология культуры. / пер. с англ. - М.: Юрист, 1995. - 479 с.

5. Философия: Энциклопедический словарь [Электронный ресурс] / под редакцией А.А. Ивина. - M.: Гардарики, 2004. - URL: http://encdic.com/philosophy/Cennost-2621/ (дата обращения 17.04.2019)

6. Kitagawa J.M. Joachim Wach, Leben, Forschung und Lehre Leben // Joachim Wach-Verlesungen, I. - Leiden: E. J. Brill, 1963. - S. 1-31.

7. Wach J. Einführung in de Religionssoyiologie. - Tübingen: Verlag von J.C.B. Mohr (Paul Siebeck), 1931. $-98 \mathrm{p}$

8. Wach J. Sociology of religion // Essays in the History of religions / edited by Josef M. Kitagawa and Gregory D. Alles. - N.Y.: Macmillan Publishing Company, 1988. - P. 81-113.

9. Wach J. The comparative study of religions. N.Y.: Columbia university press, $1958 .-$ xlviii $+234 p$.

10. Wach J. Types of religious experience Christian and non-Christian. - Chicago: University of Chicago Press, 1951. - xvi +275 p. 